\title{
Flow cytometric enumeration of marine viral populations at low abundances
}

\author{
K. D. A. Mojica ${ }^{1, *}$, C. Evans ${ }^{1,3}$, C. P. D. Brussaard ${ }^{1,2}$ \\ ${ }^{1}$ Department of Biological Oceanography, NIOZ-Royal Netherlands Institute for Sea Research, PO Box 59, \\ 1790 AB Den Burg, Texel, The Netherlands \\ ${ }^{2}$ Aquatic Microbiology, Institute for Biodiversity and Ecosystem Dynamics, University of Amsterdam, PO Box 94248, \\ 1090 GE Amsterdam, The Netherlands \\ ${ }^{3}$ Present address: National Oceanography Centre, European Way, Southampton, SO14 3ZH, UK
}

\begin{abstract}
Flow cytometric enumeration has advanced our ability to analyze aquatic virus samples and thereby our understanding of the ecological role viruses play in the oceans. However, low virus abundances are underestimated using the current flow cytometry (FCM) protocol. Our results revealed that low dilutions $(<30$-fold) not only decreased the total virus count but also limited the ability to differentiate between virus clusters. Here we report a simple and efficient method optimization for improving virus counts and optical resolution at low abundances. Raising the $\mathrm{pH}$ of the Tris-EDTA (TE) buffer to 8.2 successfully countered the effect of insufficient buffering capacity at low dilutions, which is caused by the higher proportion of acidic glutaraldehyde fixative in the final sample. The higher buffer $\mathrm{pH}$ did not interfere with virus counts at higher dilutions. We therefore recommend amendment of the standard FCM aquatic virus enumeration protocol using a TE buffer with $\mathrm{pH} 8.2$ as a simple and efficient improvement.
\end{abstract}

KEY WORDS: Flow cytometry · Low abundance · Virus enumeration

\section{INTRODUCTION}

Viruses are abundant, ubiquitous, and essential components of aquatic systems, playing key roles in the mortality of microbes, biogeochemical cycling, structuring host community composition, and genetic exchange between microbes (Sullivan et al. 2006, Suttle 2007, Brussaard et al. 2008b). Natural virus populations have been found to be highly dynamic, changing rapidly in abundance and diversity over a broad range of environments (Suttle \& Chan 1994, Brussaard et al. 2008a, Winget \& Wommack 2009). Therefore, aquatic viral ecology necessitates rapid and reliable methods for enumerating viruses.

The advent of flow cytometry (FCM) has vastly advanced our understanding of aquatic viral ecology (Brussaard 2004). Traditionally, viruses have been counted using culture-based methods (Cottrell \& Suttle 1995, Suttle \& Chan 1995), transmission electron microscopy (Bergh et al. 1989, Wommack et al. 1992, Bratbak et al. 1993), and epifluorescence microscopy (Hara et al. 1991, Hennes \& Suttle 1995, Noble \& Fuhrman 1998) in combination with nucleic acid-specific staining. However, these methods are limited by either the availability of a host system, cost, or time (Marie et al. 1999, Brussaard 2004, Duhamel \& Jacquet 2006). FCM brought about immense improvements in the speed and accuracy of both the detection and enumeration of viruses in natural systems (Brussaard et al. 2000, Brussaard 2004). Rapid counting not only allows the analysis of more samples per time unit but also improves detection of stained viruses with low fluorescence compared to epifluorescence microscopy by reducing the poten- 
tial time for fading (Brussaard 2000). These improvements to the speed and accuracy of counting viruses using FCM, combined with the ability to discriminate different virus clusters (Brussaard et al. 2010), has increased the popularity of this method.

Low virus abundances (i.e. $\leq 10^{6} \mathrm{ml}^{-1}$ ), which can be found in the deep ocean or very oligotrophic waters or resulting from experimental design such as the viral production assay (Weinbauer et al. 2010), which reduces virus concentrations to permit the detection of the newly produced phage from infected bacteria, demand low dilutions in a buffer solution to obtain an optimal event rate (i.e. 200 to 800 events $\mathrm{s}^{-1}$ ) (Brussaard et al. 2010). However, studies have shown that low dilution factors for virus samples can substantially underestimate the total virus concentration (Brussaard 2004). To overcome this limitation, the current study set out to (1) identify the factor responsible for the decline in viral abundance and the nucleic acid-specific staining signal at low dilution factors, and (2) improve the existing flow cytometric analysis method for the accurate enumeration of viruses present in natural samples at low abundances.

\section{MATERIALS AND METHODS}

\section{Samples and FCM}

FCM was used to measure the viral abundance in natural samples. Two geographical locations, i.e. the North Atlantic Ocean (STRATIPHYT summer 2009 cruise, samples obtained from 125 to $175 \mathrm{~m}$, Stns 13 to 15 , in the waters located between 42.3 to $44.3^{\circ} \mathrm{N}$ and $12.7^{\circ} \mathrm{W}$ ) and the Southern Ocean (GEOTRACES austral spring 2008 cruise, samples obtained from $50 \mathrm{~m}$ in the central Weddell Sea at $66.2^{\circ} \mathrm{S}$ and $30.9^{\circ} \mathrm{W}$ ) were used as model systems. These locations were chosen based on the abundance of viruses at these sites, which was around $10^{6} \mathrm{ml}^{-1}$ but sufficient to remain within the limits of measurement (i.e. 100 to 1100 events s$^{-1}$ ) at a 50-fold dilution (Marie et al. 1999, Brussaard 2004). As the viral abundance of these samples was not sufficient to test the influence of Tris-EDTA (TE) buffer $\mathrm{pH}$ on viral abundance at high dilution factors (i.e. 200- and 1000-fold), natural virus communities from the southern North Sea were used. Additionally, the effect of TE buffer pH 8.2 versus 8.0 was tested on natural virus communities originating from less saline locations, i.e. 2 estuaries (Wadden Sea and Baltic Sea) and 2 local freshwater ponds with very different $\mathrm{pH}$ values. To test these lat- ter communities at a 10-fold dilution, natural samples were diluted $(100 \times)$ using virus-free ultrafiltrate water from the same location prior to fixation (attained from tangential flow diafiltration using a 30 kDa VivaFlow 200 cartridge, Sartorius Stedim Biotech).

The method presented by Brussaard (2004) for counting viruses using flow cytometry was used as a standard. Briefly, samples were fixed with $25 \%$ glutaraldehyde (EM grade, Sigma-Aldrich) at a final concentration of $0.5 \%$ for 15 to $30 \mathrm{~min}$ at $4^{\circ} \mathrm{C}$ and subsequently flash frozen and stored at $-80^{\circ} \mathrm{C}$ until analysis. In addition, formaldehyde (1 and $2 \%$ final concentration) fixation was also tested for a loss of virus counts at low dilution factors. Formaldehyde has been used for flow cytometric analysis and epifluorescence microscopy of natural virus samples and reported to show comparable counts to glutaraldehyde (Robinson et al. 1999, Patel et al. 2007)

In addition to diluting thawed samples in the standard TE buffer ( $\mathrm{pH} 8.0,10 \mathrm{mM}$ Tris-HCl, $1 \mathrm{mM}$ EDTA; Roche), Tris-borate-EDTA (TBE) $(1 \times, 89 \mathrm{mM}$ Tris, $89 \mathrm{mM}$ boric acid, $2 \mathrm{mM}$ EDTA) and Trisacetate-EDTA (TAE) $(1 \times, 40 \mathrm{mM}$ Tris, $20 \mathrm{mM}$ acetic acid, 1 mM EDTA) buffers were also tested. These buffers are recommended alongside TE buffer by the manufacturer of SYBR Green I (Life Technologies) and have not been tested previously. Other dilution solutions that have been tested (i.e. Tris, phosphatebuffered saline, $\mathrm{dH}_{2} \mathrm{O}$, and seawater) have shown that TE buffer provided the highest virus counts and green fluorescence signal (Brussaard 2004). After dilution in buffer solution, samples were stained with the nucleic acid-specific green fluorescence dye SYBR Green I at a final concentration of $5 \times 10^{-5}$ the commercial stock concentration (Life Technologies) and heated at $80^{\circ} \mathrm{C}$ for $10 \mathrm{~min}$ in the dark. Cooled samples (5 min, room temperature) were analyzed using a $15 \mathrm{~mW}$ bench-top Becton-Dickinson FACSCalibur flow cytometer equipped with an air-cooled $488 \mathrm{~nm}$ argon laser and Milli-Q water (18 M) as sheath fluid. The discriminator was set on green fluorescence, with the threshold at the lowest companyset level. The maximum voltage, at which no electronic or laser noise was detected, was used for the green fluorescence channel photo-multiplier according to the recommendations of Brussaard et al. (2010). Samples were analyzed for $1 \mathrm{~min}$ at a medium flow rate $\left(\sim 40 \mu \mathrm{min}^{-1}\right)$, after which the listmode files were analyzed using CYTOWIN (Vaulot 1989); www. sb-roscoff.fr/Phyto/index.php?option=com_content \& task=view\&id=72\&Itemid=123). Virus counts were corrected for blanks consisting of TE buffer and 
SYBR Green I prepared and analyzed in an identical manner to the samples. TE blanks were not found to be significantly different from blanks consisting of virus-free seawater samples generated by $30 \mathrm{kDa}$ ultrafiltrate (2-sample $t$-test; $\mathrm{df}=6$; ns).

\section{Treatments}

Natural virus samples were subjected to different levels of sample dilution, salinity, and $\mathrm{pH}$ of $\mathrm{TE}$ buffer (Table 1), as well as type of fixative and type of buffer solution. The influence of salinity, which will vary according to the proportion of seawater present in the final sample because of the level of dilution with buffer, was tested. North Atlantic seawater ultrafiltrate (salinity 36.0) attained from tangential flow diafiltration (30 kDa VivaFlow 200, Sartorius Stedim Biotech) was subjected to slow evaporation using moderate heat until a maximum salinity of 41 was obtained. A range of salinities (Table 1) was then achieved by subsequent addition of increasing amounts of sterile ultrapure Milli-Q water (18 M), while maintaining the ratios for constituent ions. Salinity was monitored using a digital conductivity meter (GMH 3430, Greisinger). The ultrafiltrate saline solutions were then used to dilute the North Atlantic viruses samples 5-fold, after which the samples were 10-fold diluted in the TE buffer at 3 different $\mathrm{pH}$ levels $(7.8,7.9$, and 8.1). The result was a final dilution factor of 50, with the salinity impact of a factor 10 dilution.

The staining efficiency of SYBR Green I has been shown to be affected by $\mathrm{pH}$, with significant drops in sensitivity occurring when $\mathrm{pH}$ is greater than 8.3 or less than 7.5 (Life Technologies, technical specifications). To test the effect of buffer $\mathrm{pH}$ on viral abundances measured at low dilutions, a range of $\mathrm{pH}$ was created by the addition of either $0.1 \mathrm{M} \mathrm{NaOH}$ (J. T. Baker) or $0.1 \mathrm{M} \mathrm{HCl}$ (J. T. Baker) to a working stock buffer solution. In addition, stepwise additions of $0.1 \mathrm{M}$ $\mathrm{HCl}$ to glutaraldehyde-fixed North Atlantic samples at higher dilution (50x dilution in TE buffer at $\mathrm{pH} 8.0$ ) were performed to verify the direct effect of $\mathrm{pH}$, inde-

Table 1. Treatments investigated for effect on virus enumeration by flow cytometry

\begin{tabular}{|ll|}
\hline Treatment & Level \\
\hline Dilution & $10 \times, 15 \times, 20 \times, 30 \times, 50 \times$ \\
Salinity & $26,28,30,32,34,36,38,40$ \\
pH of TE buffer & $7.8,7.9,8.0,8.1,8.2,8.3,8.4,8.5$ \\
\hline
\end{tabular}

pendent of the increase in glutaraldehyde. $\mathrm{pH}$ was monitored using a laboratory $\mathrm{pH}$ meter (827 $\mathrm{pH}$ lab with pH probe [6.0258.010], Metrohm Applikon). Total alkalinity was determined on a fixed-volume sample of unfiltered seawater poisoned with mercury chloride (Sigma-Aldrich) $(0.05 \%$ final concentration of saturated mercury chloride). Potentiometric titration of seawater was performed using an open cell and computer-controlled titration instrument (Titrino DMP 785, Metrohm Applikon) and 0.1 M HCL + $0.6 \mathrm{M} \mathrm{NaCl}$ (Vstep of $0.05 \mathrm{ml}$ ). Total alkalinity was then calculated using the simple Gran and non-linear least-squares method (Dickson et al. 2003).

\section{Statistical analysis}

Statistical analyses of different treatments were performed using R statistical software (R Development Core Team 2012). Assumptions for ANOVA were verified by the Shapiro-Wilks test for normality and the Bartlett's test for constancy of variance. If significant $(\mathrm{p}<0.01)$ deviations were found, the BoxCox transformation coefficient was used to find the optimal transformation. In the cases where lambda equaled 1, indicating that no transformations would improve data, non-parametric Kruskal-Wallis analysis was used. During ANOVA, all variables were initially included in the model with their interaction terms, and when necessary, the model was trimmed to remove any non-significant terms and interactions. When applicable, post-hoc analysis using Tukey's pairwise comparisons was performed. A probability of $\alpha<0.01$ was used to conclude that the treatment levels differed significantly in the effect on the measured value. In the case where the effects of salinity (8 levels) and TE buffer pH (3 levels) were considered together, a factorial ANOVA model was fitted to data. Assumptions of equal variance for 2-sample Student's $t$-tests were verified by Fisher's F-test. When significant $(\mathrm{p}<0.01)$ deviations were found, a nonparametric Wilcoxon rank-sum test was used.

\section{RESULTS AND DISCUSSION}

To optimize the staining of the viruses and avoid coincidence of particles during flow cytometric analysis, samples are diluted using TE buffer (Brussaard 2004). However, the enumeration of marine viruses in aquatic systems by FCM has been reported to be limited by a reduced efficiency in counts when the dilution in TE buffer is below 20-fold (Brussaard 2004). 
Three virus groups (V1 to V3, Fig. 1) were differentiated based on green fluorescence and side scatter properties using bivariate scatter plots (Brussaard et al. 2010). We found that the dilution factor (i.e. 10 to $50 \times$ ) of natural virus samples from the North Atlantic in TE buffer at the standard $\mathrm{pH} 8.0$ had a significant effect on the measured abundance of total viruses (1-way ANOVA; $\mathrm{p}<0.0001 ;$ Fig 2A) and V1 group viruses (1-way ANOVA; $\mathrm{p}<0.0001$; Fig 2B). Viral abundances dropped by 23,13 , and $5 \%$ for total virus counts and by 66,49 , and $19 \%$ for the V1 cluster when diluted 10-, 15-, and 20-fold, respectively.

Two constituents of a sample that could potentially account for the reduction in viral abundance at lower dilution are the increased proportion of the seawater

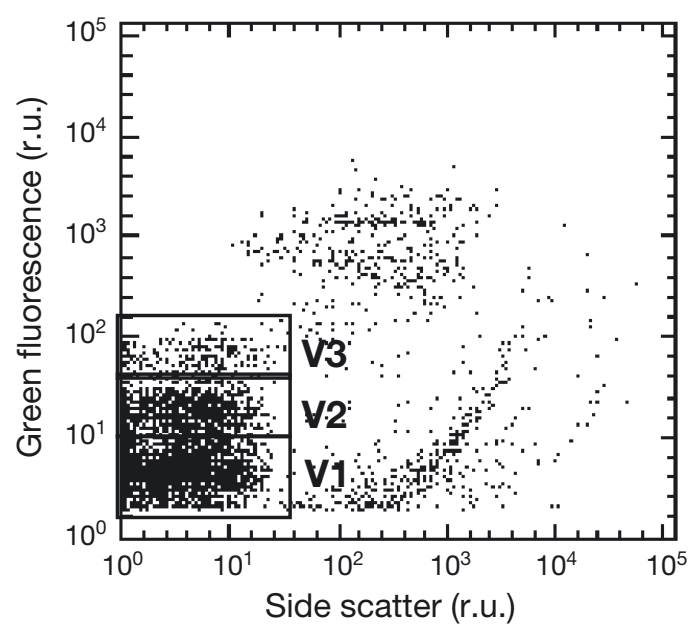

Fig. 1. Bivariate scatter plot of green fluorescent versus side scatter (relative units, r.u.) illustrating the V1, V2, and V3 virus groups, which together make up total viruses. Virus sample was obtained from the North Atlantic 2009 summer STRATIPHYT cruise (Stn 6, $60 \mathrm{~m}$ ) and diluted 100x in TE buffer of $\mathrm{pH} 8.0$ and the fixative. Salinity, simulating the increasing proportion of seawater sample, did not significantly (factorial ANOVA) impact total virus or V1 counts. However, the $\mathrm{pH}$ of the TE buffer used for diluting samples was found to have a significant effect on the V1 group and total virus counts (both $\mathrm{p}<0.0001$ ). Adding glutaraldehyde ( $0.5 \%$ final concentration) to a $30 \mathrm{kDa}$ ultrafiltrate seawater sample and diluting 10-fold in TE buffer at $\mathrm{pH} 8.0$ demonstrated that the reduction in virus counts at low dilution was caused by the increased proportion of glutaraldehyde in the sample leading to a reduction in the $\mathrm{pH}$, which was not sufficiently buffered against when using TE buffer at $\mathrm{pH}$ 8.0. The final sample $\mathrm{pH}$ was found to be 6.85 , which fell out of the optimal range of 7.5 to 8.0 reported by Brussaard (2004) and the optimum $\mathrm{pH}$ of 8.0 recommended by manufacturer of SYBR Green I (Life Technologies, technical specifications). Stepwise additions of $\mathrm{HCl}$ to glutaraldehyde-fixed North Atlantic samples at a higher dilution (50x dilution in TE buffer at $\mathrm{pH}$ 8.0) showed that the general patterns for the decline of total and V1 virus abundance could be reproduced without increasing the proportion of glutaraldehyde, supporting the assumption that $\mathrm{pH}$ was the main cause for the underestimation of counts at low dilutions.

Adjusting the $\mathrm{pH}$ of TE buffer used for dilution led to improved total virus enumeration and differentiation between the different virus clusters for the North Atlantic Ocean and Southern Ocean virus communities (Fig. 3). At 10-fold dilutions, a pH of 8.2 showed the optimal balance between counts and staining signature. Raising the TE buffer $\mathrm{pH}$ from 8.0 to 8.2 at low dilutions resulted in an increase in the green fluorescence intensity of virus particles and subsequently increased the proportion of viruses that
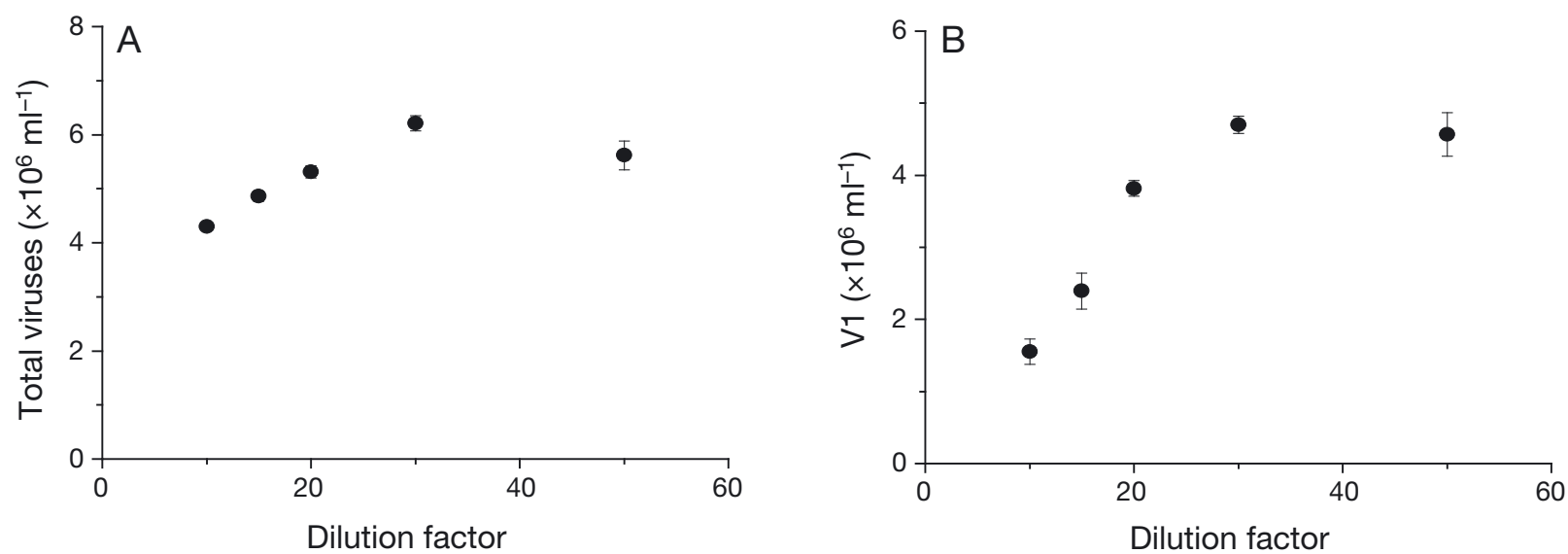

Fig. 2. (A) Total virus and (B) V1 abundance enumerated over a dilution range of 10 to 50× using TE buffer pH of 8.0. Error bars represent standard deviations $(\mathrm{N}=3)$ 

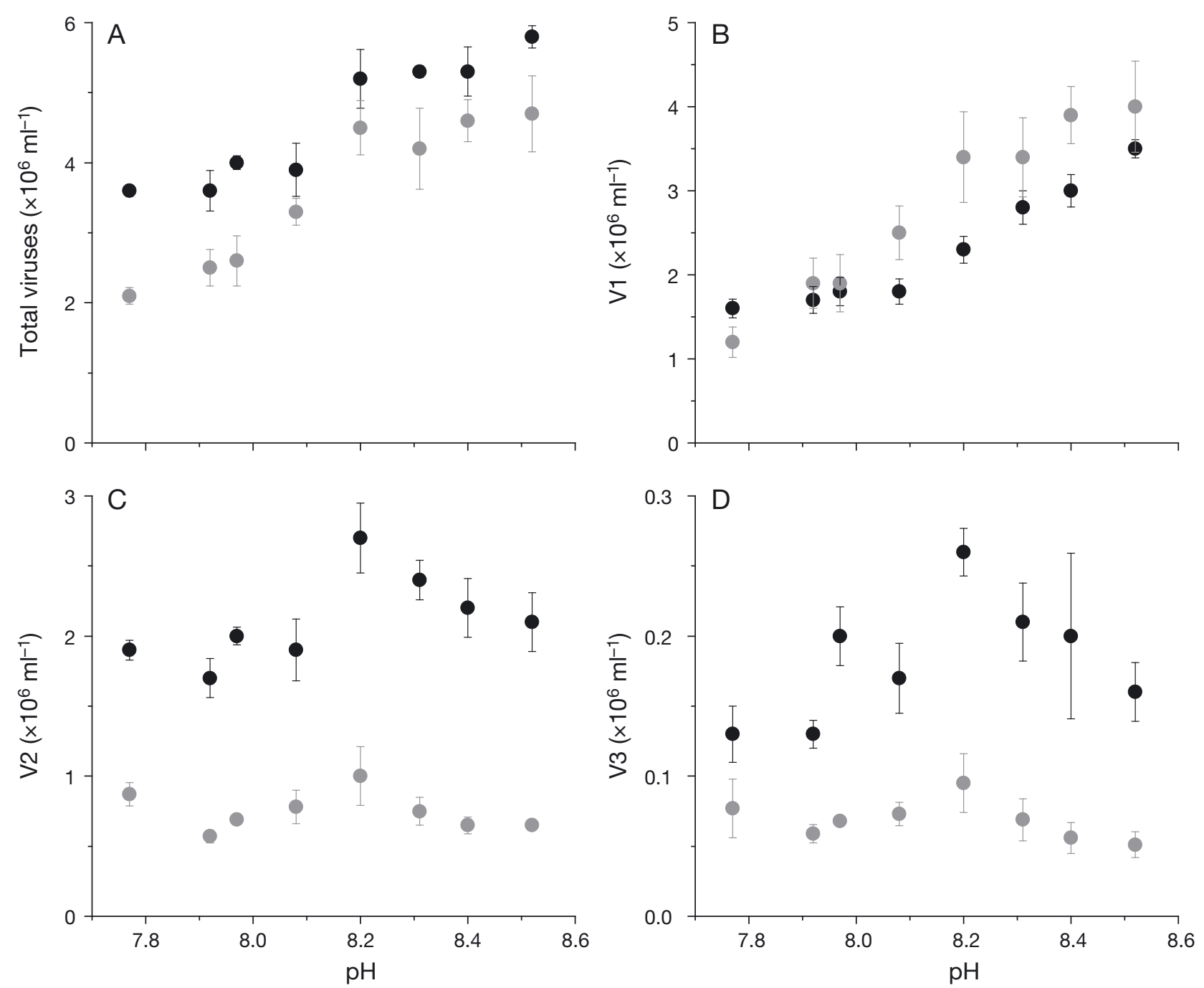

Fig. 3. Virus abundance enumerated at a 10-fold dilution using TE buffer at different pH levels. (A) Total virus abundance, (B) V1 virus abundance, (C) V2 virus abundance, and (D) V3 virus abundance in Southern Ocean (O) and North Atlantic (O) seawater. Error bars represent standard deviations $(\mathrm{N}=4)$

could be detected. The degree to which $\mathrm{pH}$ affected viral abundance, however, varied across the different sample locations, i.e. the 10-fold diluted North Atlantic virus samples had a proportionally higher reduction of total virus and V1 abundance at lower $\mathrm{pH}$ values compared to the Southern Ocean samples (Fig. 3A,B). Increasing the TE buffer $\mathrm{pH}$ to 8.2 when diluting 10-fold improved V1 and total virus counts by 28 and $31 \%$ in Southern Ocean samples and by 78 and $69 \%$ in North Atlantic Ocean samples, respectively, when compared to TE $\mathrm{pH}$ 8.0. The abundance of V2 and V3 groups of the North Atlantic samples remained relatively stable, with a small increase occurring in TE buffer $\mathrm{pH} 8.2$ (Fig. 3C,D). However, the relative importance of V1 to V3 in Southern Ocean and North Atlantic samples remained compa- rable between TE $\mathrm{pH} 8.2$ and 8.0, and as a consequence, there was little effect on the average green fluorescence. These results were not affected by the use of different FACSCalibur flow cytometers, as measurements for this experiment were performed simultaneously on 2 separate FACSCalibur cytometers and gave good correlations between counts ( 0.96 for the Southern Ocean and 0.93 for the North Atlantic samples).

When using TE buffer at $\mathrm{pH}$ 8.2, the dilution factor (i.e. 10 to $50 \times$ ) no longer had a significant effect on the viral abundance (Kruskal-Wallis; df $=8$; ns), demonstrating the effectiveness of $\mathrm{pH} 8.2$ to alleviate the underestimation of virus counts at low dilutions. To verify that increased buffer $\mathrm{pH}$ did not affect viral counts at higher dilutions and would therefore be 
applicable as a general method improvement, natural virus samples were diluted in TE buffer $\mathrm{pH} 8.0$ and 8.2 at a 50 -fold dilution for North Atlantic samples and at both a 200- and 1000-fold dilution for North Sea samples. At these high dilution factors, no significant differences ( 2 sample $t$-test; $\mathrm{df}=8$ ) were found in V1 or total viral abundance measured between samples diluted in TE buffer $\mathrm{pH} 8.0$ and 8.2 for either location.

The effect of TE buffer $\mathrm{pH} 8.2$ versus 8.0 was further tested on natural virus communities from different low salinity environments, i.e. 2 estuaries (Wadden Sea and Baltic Sea) and 2 freshwater ponds (Table 2). Increasing the $\mathrm{pH}$ of TE buffer to 8.2 had a relatively low $(8 \%)$ but significant $(2$-sample $t$-test; $\alpha=0.01 ; \mathrm{N}=4$ ) positive effect on the viral abundance measured in a 10-fold diluted sample from the Baltic Sea. However, no significant effect of TE buffer $\mathrm{pH}$ was found for the other locations tested (2-sample $t$-test; $\alpha=0.01 ; N=4$ ). The lack of effect for the Wadden Sea estuary was surprising considering that the alkalinity and $\mathrm{pH}$ of this water nearly matched that of the North Atlantic sample. The differences in the effect of pH 8.2 on viral abundance between samples are most likely dependent on variation in the staining sensitivity of the viral communities at these different locations.

The use of formaldehyde ( 1 and $2 \%$ final concentration) as a fixative was tested as an alternative to glutaraldehyde for both North Atlantic and Wadden Sea samples; however, no significant improvements were found (2-sample $t$-test; $\alpha=0.01 ; N=3$ ). Considering that commercially available formaldehyde ( $37 \%$ ) has a $\mathrm{pH}$ range of 2.8 to 4.0 , it presented the

Table 2. Effect of TE buffer pH 8.2 (compared to 8.0) on total virus abundance in samples from various environments measured at a 10-fold dilution. TAlk: total alkalinity $\left(\mathrm{Meq}^{-1}\right)$. Significant values in bold. Pond samples originate from Texel, Netherlands

\begin{tabular}{|c|c|c|c|c|}
\hline Sample & Salinity & $\mathrm{pH}$ & TAlk & $\%$ Change \\
\hline North Atlantic & 35.7 & 7.87 & 2.37 & 69 \\
\hline Southern Ocean & 34.3 & 8.09 & 2.41 & 31 \\
\hline Wadden $\mathrm{Sea}^{\mathrm{a}}$ & 25.3 & 7.87 & 2.36 & 0 \\
\hline Baltic Sea ${ }^{b}$ & 5.7 & 8.15 & 1.59 & 8 \\
\hline $\mathrm{NIOZ}$ pond $^{\mathrm{a}}$ & 0.3 & 9.59 & 1.34 & 1 \\
\hline Den Hoorn pond ${ }^{a}$ & 0.4 & 7.94 & 2.17 & 0 \\
\hline \multicolumn{5}{|c|}{$\begin{array}{l}\text { a Samples were pre-diluted using virus-free sample to } \\
\text { allow for } 10 \text {-fold dilution. Salinity, } \mathrm{pH} \text {, and alkalinity are } \\
\text { reported for undiluted sample }\end{array}$} \\
\hline \multicolumn{5}{|c|}{$\begin{array}{l}\text { bViral production sample (Weinbauer et al. 2010) origi- } \\
\text { nating from a Baltic Sea mesocosm experiment }\end{array}$} \\
\hline
\end{tabular}

same methodological issues as glutaraldehyde $(25 \%$; $\mathrm{pH}$ range 3.0 to 4.0 ) when measuring at low dilutions in TE buffer $\mathrm{pH}$ 8.0. Moreover, the use of alternative buffer solutions (TAE and TBE, recommended in addition to TE by the manufacturer of SYBR Green I) did not lead to significant improvements in counts at low dilutions compared to dilution using TE buffer.

In summary, increasing the $\mathrm{pH}$ of TE buffer has the potential to significantly improve the efficiency of virus counts in aquatic systems when diluted to 10 fold dilution. TE buffer with a $\mathrm{pH}$ of 8.2 was found to be optimal, as it leads to significantly higher viral abundance (total and V1) compared to lower $\mathrm{pH}$ values, while providing the highest V2 and V3 counts. The beneficial effect of increased $\mathrm{pH}$ is not ubiquitous or consistent across all aquatic systems and does not appear to be dependent on sample $\mathrm{pH}$ or alkalinity, indicating that the magnitude of effect is dependent on the viral communities present in the sample. TE buffer at $\mathrm{pH} 8.2$ did not have a significant negative effect on viral abundance in unaffected samples, was not found to affect the virus abundances at higher dilutions, and thus can be adopted for general use. While maintaining the best and most commonly used method for fixation and analysis, the modification in the $\mathrm{pH}$ of TE buffer is a simple and effective method to achieve vital improvement on viral enumeration at low dilutions. Increasing the accuracy and precision of virus counts in systems with low abundances has the potential to expand (or even open) the field of marine viral ecology, which is currently limited by the inability to measure viruses at low numerical abundances.

Acknowledgements. We thank Katharine J. Crawfurd for providing us with the viral production sample from the Baltic Sea mesocosm. This research was supported by the Earth and Life Sciences Foundation (ALW), which is subsidized by the Netherlands Organization for Scientific Research (NWO).

\section{LITERATURE CITED}

Bergh O, Borsheim KY, Bratbak G, Heldal M (1989) High abundance of viruses found in aquatic environments. Nature 340:467-468

Bratbak G, Egge JK, Heldal M (1993) Viral mortality of the marine alga Emiliania huxleyi (Haptophyceae) and termination of algal blooms. Mar Ecol Prog Ser 93: 39-48

> Brussaard CPD (2004) Optimization of procedures for counting viruses by flow cytometry. Appl Environ Microbiol 70:1506-1513

Brussaard CPD, Marie D, Bratbak G (2000) Flow cytometric detection of viruses. J Virol Methods 85:175-182 
Brussaard CPD, Timmermans KR, Uitz J, Veldhuis MJW (2008a) Virioplankton dynamics and virally induced phytoplankton lysis versus microzooplankton grazing southeast of the Kerguelen (Southern Ocean). Deep-Sea Res 55:752-765

Brussaard CPD, Wilhelm SW, Thingstad TF, Weinbauer MG and others (2008b) Global-scale processes with a nanoscale drive: the role of marine viruses. ISME $\mathrm{J} 2$ : 575-578

Brussaard CPD, Payet JP, Winter C, Weinbauer M (2010) Quantification of aquatic viruses by flow cytometry. In: Wilhelm SW, Weinbauer MG, Suttle CA (eds) Manual of aquatic viral ecology. American Society of Limnology and Oceanography, Waco, TX, p 102-109

> Cottrell MT, Suttle CA (1995) Dynamics of a lytic virus infecting the photosynthetic marine picoflagellate Micromonas pusilla. Limnol Oceanogr 40:730-739

Dickson AG, Afghan JD, Anderson GC (2003) Reference materials for oceanic $\mathrm{CO}_{2}$ analysis: a method for the certification of total alkalinity. Mar Chem 80: 185-197

> Duhamel S, Jacquet S (2006) Flow cytometric analysis of bacteria and virus-like particles in lake sediments. J Microbiol Methods 64:316-332

> Hara S, Terauchi K, Koike I (1991) Abundance of viruses in marine waters: assessment by epifluorescence and transmission electron microscopy. Appl Environ Microbiol 57: 2731-2734

Hennes KP, Suttle CA (1995) Direct counts of viruses in natural waters and laboratory cultures by epifluorescence microscopy. Limnol Oceanogr 40:1050-1055

Marie D, Brussaard CPD, Thyrhaug R, Bratbak G, Vaulot D (1999) Enumeration of marine viruses in culture and natural samples by flow cytometry. Appl Environ Microbiol 65:45-52

Noble RT, Fuhrman JA (1998) Use of SYBR Green I for rapid epifluorescence counts of marine viruses and bacteria. Aquat Microb Ecol 14:113-118

Patel A, Noble RT, Steele JA, Schwalbach MS, Hewson I,

Editorial responsibility: Josep Gasol,

Barcelona, Spain
Fuhrman JA (2007) Virus and prokaryote enumeration from planktonic aquatic environments by epifluorescence microscopy with SYBR Green I. Nat Protoc 2: 269-276

R Development Core Team (2012) R: a language and environment for statistical computing. R Foundation for Statistical Computing, Vienna

Robinson JP, Darzynkiewicz Z, Dean PN, Orfao A and others (eds) (1999) Current protocols in cytometry. John Wiley \& Sons, New York, NY

Sullivan MB, Lindell D, Lee JA, Thompson LR, Bielawski JP, Chisholm SW (2006) Prevalence and evolution of core photosystem II genes in marine cyanobacterial viruses and their hosts. PLoS Biol 4:e234

Suttle CA (2007) Marine viruses-major players in the global ecosystem. Nat Rev Microbiol 5:801-812

> Suttle CA, Chan AM (1994) Dynamics and distribution of cyanophages and their effect on marine Synechococcus spp. Appl Environ Microbiol 60:3167-3174

Suttle CA, Chan AM (1995) Viruses infecting the marine Prymnesiophyte Chrysochromulina spp: isolation, preliminary characterization and natural-abundance. Mar Ecol Prog Ser 118:275-282

Vaulot D (1989) CYTOPC: processing software for flow cytometric data. Signal Noise 2:8

Weinbauer MG, Rowe JM, Wilhelm SW (2010) Determining rates of virus production in aquatic systems by the virus reduction approach. In: Wilhelm SW, Weinbauer MG, Suttle CA (eds) Manual of aquatic viral ecology. American Society of Limnology and Oceanography, Waco, TX, p 1-8

Winget DM, Wommack KE (2009) Diel and daily fluctuations in virioplankton production in coastal ecosystems. Environ Microbiol 11:2904-2914

> Wommack KE, Colwell RR (2000) Virioplankton: viruses in aquatic ecosystems. Microbiol Mol Biol Rev 64:69-114

Wommack KE, Hill RT, Kessel M, Russekcohen E, Colwell RR (1992) Distribution of viruses in the Chesapeake Bay. Appl Environ Microbiol 58:2965-2970

Submitted: March 11, 2013; Accepted: October 2, 2013 Proofs received from author(s): December 13, 2013 